\title{
Oligometastases in prostate cancer
}

\section{Metabolic response in follow-up PSMA-PET-CTs after hypofractionated IGRT}

\author{
René Baumann $^{1}$ (D) $\cdot$ Mark Koncz $^{1} \cdot$ Ulf Luetzen $^{2} \cdot$ Fabian Krause $^{1} \cdot$ Juergen Dunst $^{1}$
}

Received: 18 April 2017 / Accepted: 6 November 2017 / Published online: 27 November 2017

(C) The Author(s) 2017. This article is an open access publication.

\begin{abstract}
Background Prostate-specific membrane antigen positron emission tomography/computed tomography (PSMAPET/ $\mathrm{CT}$ ) is a new and evolving diagnostic method in prostate cancer with special impact on treatment planning in imageguided radiotherapy (IGRT). Initial results of metabolic response in repeated PSMA PET/CTs after hypofractionated IGRT for metastatic lesions are reported here.

Materials and methods of 280 patients investigated with ${ }^{68} \mathrm{Ga}$-PSMA PET/CT in the period from 01/2014 through $12 / 2016$ in the authors' department, patients were selected according to the following criteria: oligometastatic disease at initial PSMA PET/CT defined as not more than five metastatic lesions, hypofractionated IGRT to all lesions, no systemic therapy in the last 6 months and during follow-up, and at least one follow-up PSMA PET after radiotherapy. Radiotherapy was administered to all PSMA PET-detected lesions $(\mathrm{CTV}=$ PET-GTV +1 to $2 \mathrm{~mm}$ ), mostly with $35 \mathrm{~Gy}$ in five fractions (one lesion with four fractions of $7 \mathrm{~Gy}$ due to dose constraints, two lymph nodes with $50 \mathrm{~Gy}$ in 25 fractions to an extended volume plus a boost of $7 \mathrm{~Gy} \times 2$ to the PET-positive volume). Metabolic response of irradiated lesions was evaluated on repeated PSMA PET/CTs according to PERCIST criteria. Five patients with a total number of 12 PSMA PETs matched the criteria. Patients received radiotherapy to all PET-positive lesions and had at least one (in one case three) follow-up PSMA PET exami-
\end{abstract}

Prof. Dr. Juergen Dunst

Juergen.Dunst@uksh.de

1 Dept. of Radiation Oncology, Christian-Albrechts-University Kiel, Arnold-Heller-Str. 3, 24105 Kiel, Germany

2 Dept. of Nuclear Medicine, Christian-Albrechts-University Kiel, Kiel, Germany nations after radiotherapy with an interval to the first PET of 2-15 months; the median follow-up for all patients was 11 months.

Results The mean prostate-specific antigen (PSA) values at the time of examination were $8.9 \pm 8.5 \mathrm{ng} / \mathrm{ml}$ (median $3.3 \mathrm{ng} / \mathrm{ml}$, range $0.17-21.8 \mathrm{ng} / \mathrm{ml}$ ). A total number of 18 metastatic deposits were detected. The PET-positive tumor volume was $5.9 \pm 13.3 \mathrm{~cm}^{3}$ (median $\left.1.25 \mathrm{~cm}^{3}\right)$. The mean standardized uptake value (mean $\mathrm{SUV}_{\max }$ ) of the 18 metastatic lesions decreased from $19.9 \pm 23.3$ (mean \pm $\mathrm{SD})$ prior to RT to $5.4 \pm 4.6$ at post-radiotherapy PSMA PET/CT. Using PERCIST criteria, 14 lesions (78\%) showed a metabolic response in PSMA PET with a reduction of SUV of at least $30 \%$, as well as a significant decrease in lesion size; in seven of these lesions, no uptake of ${ }^{68} \mathrm{Ga}-$ PSMA was detectable. In follow-up PET scans, only two lesions showed metabolic progression with an increase in $\mathrm{SUV}_{\max }$ yielding a local progression-free survival of $88 \%$ after 1 year. There was a correlation between the time interval after radiotherapy (median 3 months, range 1-9 months) and response $(p=0.04)$ with better metabolic response after longer follow-up.

Conclusions Preliminary results of this study show high metabolic response rates of PSMA PET-positive metastatic lesions after hypofractionated radiotherapy in follow-up PSMA PET with promising local control rates. An interval of several months may be required to fully estimate the efficacy of radiotherapy in control PSMA PET.

Keywords Prostate cancer - Oligometastases · PSMA PET · Image-guided radiotherapy $\cdot$ Metabolic response 


\section{Oligometastasen bei Prostatakarzinom}

Metabolisches Ansprechen in Follow-up-PSMA-PET/CT nach hypofraktionierter bildgeführter Strahlentherapie

\section{Zusammenfassung}

Hintergrund Die PSMA-Positronenemissionstomographie/ Computertomographie (PET/CT; PSMA: prostataspezifisches Membranantigen) ist eine neue und vielversprechende diagnostische Methode bei Prostatakarzinom mit besonderem Einfluss auf die Planung der bildgeführten Strahlentherapie (IGRT). Erste Ergebnisse bezüglich des metabolischen Ansprechens bei wiederholter PSMA-PET/CT nach hypofraktionierter IGRT von Oligometastasen werden im vorliegenden Beitrag dargestellt.

Material und Methoden In der Zeit von Januar 2014 bis Dezember 2016 wurden an unserer Klinik insgesamt 280 Patienten mit ${ }^{68} \mathrm{Ga}$-PSMA-PET/CT untersucht. Davon wurden Patienten ausgewählt, die die folgenden Kriterien erfüllten: Oligometastasierung in der ersten PSMA-PET/CT mit maximal 5 Herden, hoch dosierte hypofraktionierte IGRT für alle Herde, keine medikamentöse antihormonelle oder zytostatische Therapie in den letzten 6 Monaten und im Followup, mindestens eine PSMA-PET/CT zur Kontrolle des Ansprechens der Herde vorhanden. Alle in der PSMA-PET detektierten Herde (CTV = PET-GTV plus 1-2 mm) wurden mit der Strahlentherapie behandelt, überwiegend mit 35 Gy in 5 Fraktionen (ein Herd mit 4 Fraktionen à 7 Gy wegen einer Dosisbeschränkung, 2 Lymphknoten mit $50 \mathrm{~Gy}$ in 25 Fraktionen auf ein erweitertes Volumen plus Boost von $7 \mathrm{~Gy} \times 2$ auf das PET-positive Volumen). Das metabolische Ansprechen bestrahlter Herde wurde in wiederholten PSMA-PET/CT gemäß den PERCIST-Kriterien untersucht. Fünf Patienten mit 12 PSMA-PET-Untersuchungen erfüllten die Kriterien. Bei diesen Patienten wurden alle PETpositiven Herde mit hypofraktionierter IGRT auf das PETpositive Volumen behandelt. Sie erhielten mindestens eine (in einem Fall 3) Follow-up-PSMA-PET-Untersuchungen nach Strahlentherapie mit einem Intervall zur ersten PET von 2 bis 15 Monaten; die Follow-up-Dauer aller Patienten betrug im Median 11 Monate.

Ergebnisse Der mittlere Wert des prostataspezifischen Antigens (PSA) zum Zeitpunkt der ersten PSMA-PET/CT betrug $8,9 \pm 8,5 \mathrm{ng} / \mathrm{ml}$ (Median 3,3 ng/ml, Spanne 0,17$21,8 \mathrm{ng} / \mathrm{ml}$ ). Insgesamt wurde 18 Metastasen detektiert. Das PET-positive Tumorvolumen betrug $5,9 \pm 13,3 \mathrm{~cm}^{3}$ (Median 1,25 $\mathrm{cm}^{3}$ ).

Der mittlere „standardized uptake value“ $\left(\mathrm{SUV}_{\max }\right)$ der 18 Metastasen sank von 19,9 \pm 23,3 (Mittelwert \pm Standardabweichung) vor der Radiotherapie auf 5,4 \pm 4,6 in der PSMA-PET/CT nach Radiotherapie.

Gemäß den PERCIST-Kriterien zeigten 14 Metastasen (78\%) eine metabolische Remission in der PSMA-PET mit Reduktion des $\mathrm{SUV}_{\max }$ von mindestens $30 \%$ und ei- ner signifikanten Größenabnahme; in 7 dieser Metastasen war eine ${ }^{68} \mathrm{Ga}$-PSMA-Aufnahme nicht mehr nachweisbar. Follow-up-PET-Untersuchungen ergaben nur für 2 Herde eine metabolische Progression mit $\mathrm{SUV}_{\max }$-Anstieg; das entspricht einer lokalen Progressionsfreiheit von $88 \%$ nach einem Jahr. Es bestand ein signifikanter Zusammenhang zwischen dem Zeitintervall nach Radiotherapie (Median 3 Monate, Spanne 1-9 Monate) und dem Ansprechen $(p=0,04)$ mit besserem metabolischem Ansprechen bei längerem Intervall.

Schlussfolgerung Diese vorläufigen Ergebnisse zeigen eine hohe metabolische Ansprechrate von PSMA-PET-positiven metastatischen Herden nach hypofraktionierter Strahlentherapie in der Follow-up-PET. Die Raten der lokalen Kontrolle sind vielversprechend. Ein Intervall von mehreren Monaten erscheint notwendig, um die Wirksamkeit der Strahlentherapie in der Kontroll-PSMA-PET umfassend beurteilen zu können.

Schlüsselwörter Prostatakarzinom - Oligometastasen · PSMA-PET · Bildgeführte Strahlentherapie ·

Metabolisches Ansprechen

\section{Introduction}

Local treatment of metastatic lesions in oligometastatic cancers is a new and promising approach for many types of cancers, namely breast, colorectal, non-small cell lung and prostate cancers. Moreover, retrospective studies with stereotactic body radiotherapy to metastatic sites have reported promising results, suggesting that local therapy might be able to improve time to progression and delay the initiation of systemic therapy in oligometastatic prostate cancer [13, 17, 21]. Randomized studies in prostate cancer are ongoing.

Prostate-specific membrane antigen positron emission tomography (PSMA PET) is a new and rapidly evolving diagnostic tool for the detection of metastases in prostate cancer. PSMA is expressed in normal prostate cells, but its expression is increased in prostate cancer cells by a factor of 100- to 1000-fold [4, 22]. Expression increases with cancer stage. Thus, PSMA is an attractive tool for imaging. Initial results with an In-labelled antibody were hindered by low affinity, but recently, a more specific binding antibody labelled with Ga-68 was developed $[1,2,20]$. Several groups have reported high sensitivity and specificity rates of more than $80 \%$ up to $97 \%$ for both patient and lesion analysis [3, 5-11, 14-16, 18, 19, 23]. Lesion detection was possible even in cases of very low PSA values with a detection rate of about $40 \%$ in patients with PSA values below $0.5 \mathrm{ng} / \mathrm{ml}$. Thus, PSMA PET offers a new tool for the diagnosis of oligometastatic prostate cancer in a very early 
course of metastatic disease. Moreover, precise localization of metastatic deposits can be used as a basis for imageguided radiotherapy (IGRT) to detected sites. We report initial results with special emphasis on response in followup PET/computed tomography (CT) after high-dose IGRT of PSMA PET-detected lesions.

\section{Materials and methods}

\section{Patients}

Between January 2014 and December 2016, 280 patients with prostate cancer received at least one PSMA PET/CT examination in the authors' department. A total of 33 patients had repeated PSMA PET examinations during follow-up; the reason for performing repeated PET investigation was persisting or newly increased serum PSA level. Out of this group, patients were selected according to the following criteria: oligometastatic disease at initial PSMA PET/CT defined as not more than five metastatic lesions, hypofractionated IGRT to all PSMA PET-detected lesions, no systemic therapy in the previous 6 months and during the entire follow-up period and at least one follow-up PSMA PET after radiotherapy.

\section{PSMA PET/CT}

${ }^{68} \mathrm{Ga}$ ws obtained from a ${ }^{68} \mathrm{Ge} /{ }^{68} \mathrm{Ga}$ generator, labelled with the PSMA-11-precursor (ABX, Radeberg, Germany) and administered via an intravenous bolus injection (mean of 109.78 $\mathrm{MBq}$, range 73-148 $\mathrm{MBq}$ ). For the examination of the patients of this study, a cross-calibrated dedicated PET/CT system, Biograph mCT 40 (Siemens, Erlangen, Germany) was used and a standard acquisition protocol with a whole-body scan (skull base to upper thighs) starting between 58 and 95 min (mean: $70.6 \mathrm{~min}$.) p. i. and three examinations were additionally performed between 120 and $150 \mathrm{~min}$ (mean:130 min.) p.i. as part-body scans. Image data analysis was performed using commercially available software (Siemens, Erlangen, Germany). For the calculation of the $\mathrm{SUV}_{\max }$, the volume-of-interest technique was used around the areas with an increased tracer uptake in multiplanar imaging.

PSMA PET during follow-up was not performed routinely, but only in case of repeated increase in serum PSA.

\section{Radiotherapy}

Treatment decisions were based on multidisciplinary case discussions and the decision on local treatment was made with the objective to avoid and postpone systemic therapy. Radiotherapy was administered to all PSMA PET-detected lesions. The clinical target volume (CTV) was defined as the gross tumor volume (GTV) visible on PSMA PET (volume $50 \%$ of $\left.\mathrm{SUV}_{\max }\right)$ plus a safety margin of $2 \mathrm{~mm}(\mathrm{CTV}=\mathrm{PET}-$ $\mathrm{GTV}+2 \mathrm{~mm}$; safety margin of $1 \mathrm{~mm}$ in selected anatomic sites, e. g. vertebrae). All patients were treated at a Varian TrueBeam STX with daily IGRT and (in selected cases) use of the stereotactic Novalis STX system using standard immobilization devices. The standard fractionation regimen for oligometastatic disease was five fractions with a $7 \mathrm{~Gy}$ fraction dose. In one patient, two PET-positive lymph node metastases were treated with $50 \mathrm{~Gy}$ in conventional fractionation to an extended volume covering the node areas followed by a boost of $7 \mathrm{~Gy} \times 2$ to the PET-positive lymph nodes. In one patient, a single PET-positive lymph node adjacent to the esophagus was treated with four fractions of $7 \mathrm{~Gy}$ due to dose constraints. Treatment was given on consecutive working days without interruptions except at weekends.

\section{Response evaluation}

For response evaluation, follow-up PSMA PETs were compared to the initial PSMA PET prior to radiotherapy. For the evaluation of metabolic response, the standard RECIST criteria are not useful. For fluorodeoxyglucose (FDG)-PET, a modification to the RECIST criteria, the PERCIST criteria, was recommended [24]. Although such specific response criteria have not yet been published for PSMA PET, PERCIST offers the best system currently available for response evaluation of PET data and was therefore used. Thus, metabolic response was defined as a reduction in $\mathrm{SUV}_{\max }$ of at least $30 \%$ with no increase in lesion size.

\section{Statistical analysis}

Data were analyzed using SPSS with descriptive statistics and univariate analysis. Multivariate analysis was not performed due to sample size.

The study was approved by the ethics committee of the Medical Faculty of the Christian-Albrecht University Kiel.

\section{Results}

\section{Patients and treatment characteristics}

Five patients fulfilled the criteria; all patients had oligometastatic disease after successful primary treatment (Table 1$)$. None of the patients had received systemic treatment within the previous 6 months or during follow-up after radiotherapy. Four patients had one and one patient had three follow-up PSMA PET/CTs with intervals to the first PET of 2-15 months. The median follow-up of the 
Table 1 Characteristics of patients and treated metastatic lesions

\begin{tabular}{|c|c|c|c|c|c|c|c|}
\hline \multirow{2}{*}{$\begin{array}{l}\text { Patient } \\
\text { ID/age } \\
\text { (years) }\end{array}$} & \multirow{2}{*}{$\begin{array}{l}\text { Characteristics of } \\
\text { initial tumor and } \\
\text { primary treatment }\end{array}$} & \multicolumn{4}{|c|}{ Characteristics of metastatic lesion in first PSMA PET } & \multirow[b]{2}{*}{$\begin{array}{l}\text { Interval } \\
\text { between } \\
\text { radiotherapy } \\
\text { and second } \\
\text { PSMA PET } \\
\text { (months) }\end{array}$} & \multirow{2}{*}{$\begin{array}{l}\text { Metabolic } \\
\text { response }\end{array}$} \\
\hline & & Site & $\begin{array}{l}\text { Volume } \\
\left(\mathrm{cm}^{3}\right)\end{array}$ & SUVmax & $\begin{array}{l}\text { IGRT frac- } \\
\text { tionation }\end{array}$ & & \\
\hline \multirow[t]{3}{*}{ HD, 66} & \multirow{3}{*}{$\begin{array}{l}\text { pT3b R1 pN1 } \\
\text { Gleason } 9 \\
\text { Radical } \\
\text { prostatectomy }\end{array}$} & \multirow{3}{*}{$\begin{array}{l}\text { TH } 7 \\
\text { Right humerus } \\
\text { rib }\end{array}$} & 3.5 & 61.47 & $7.0 \mathrm{~Gy} \times 5$ & 9.8 & $\mathrm{mR}$ \\
\hline & & & 3.2 & 90.24 & $7.0 \mathrm{~Gy} \times 5$ & 9.8 & $\mathrm{mR}$ \\
\hline & & & 5.1 & 23.90 & $7.0 \mathrm{~Gy} \times 5$ & 9.8 & $\mathrm{mR}$ \\
\hline \multirow[t]{6}{*}{$\mathrm{RB}, 72$} & \multirow{6}{*}{$\begin{array}{l}\text { pT3 R1 pN1 } \\
\text { Gleason } 9 \\
\text { Radical } \\
\text { prostatectomy + } \\
\text { XRT to prostate } \\
\text { bed + } 6 \text { months } \\
\text { ADT }\end{array}$} & Rib & 0.1 & 3.17 & $7.0 \mathrm{~Gy} \times 5$ & 5.0 & $\mathrm{mR}$ \\
\hline & & Rib & 1.9 & 5.18 & $7.0 \mathrm{~Gy} \times 5$ & 5.0 & $\mathrm{mR}$ \\
\hline & & Pelvic node & 1.1 & 7.32 & $\begin{array}{l}2.0 \mathrm{~Gy} \times 25+ \\
7 . \mathrm{Gy} \times 2\end{array}$ & 2.9 & $\mathrm{mR}$ \\
\hline & & Pelvic node & 0.8 & 3.98 & $\begin{array}{l}2.0 \mathrm{~Gy} \times 25+ \\
7 . \mathrm{Gy} \times 2\end{array}$ & 2.9 & $\mathrm{mR}$ \\
\hline & & Th 9 & 1.2 & 6.78 & 7.0 Gy x 5 & 4.2 & $\mathrm{mR}$ \\
\hline & & $\begin{array}{l}\text { Mediastinal } \\
\text { node }\end{array}$ & 1.5 & 5.33 & $7.0 \mathrm{~Gy} \times 4$ & 2.2 & Progressive \\
\hline \multirow[t]{5}{*}{ MH, 64} & \multirow{5}{*}{$\begin{array}{l}\text { pT3 R1 pN2 } \\
\text { Gleason } 9 \\
\text { Radical } \\
\text { prostatectomy + } \\
\text { XRT to prostate } \\
\text { bed }+6 \text { months } \\
\text { ADT + } 4 \text { months } \\
\text { dendritic cells }\end{array}$} & Iliac bone & 14.8 & 18.59 & $7.0 \mathrm{~Gy} \times 5$ & 3.7 & Stable \\
\hline & & Iliac bone & 1.3 & 10.76 & $7.0 \mathrm{~Gy} \times 5$ & 3.7 & $\mathrm{mR}$ \\
\hline & & L 3 & 1.6 & 6.27 & $7.0 \mathrm{~Gy} \times 5$ & 3.7 & $\mathrm{mR}$ \\
\hline & & Scapula & 0.5 & 3.99 & $7.0 \mathrm{~Gy} \times 5$ & 3.7 & Progressive \\
\hline & & $\begin{array}{l}\text { Mediastinal } \\
\text { node }\end{array}$ & 6.6 & 9.28 & $7.0 \mathrm{~Gy} \times 5$ & 3 & Stable \\
\hline \multirow[t]{3}{*}{ MP, 77} & \multirow{3}{*}{$\begin{array}{l}\text { pT2 pN1 } \\
\text { Radical } \\
\text { prostatectomy }\end{array}$} & Rib & 2.3 & 14.26 & $7.0 \mathrm{~Gy} \times 5$ & 15 & $\mathrm{mR}$ \\
\hline & & Sacrum & 1.6 & 38.25 & $7.0 \mathrm{~Gy} \times 5$ & 15 & $\mathrm{mR}$ \\
\hline & & L4 & 58.8 & 44.57 & $7.0 \mathrm{~Gy} \times 5$ & 15 & $\mathrm{mR}$ \\
\hline KT, 78 & $\begin{array}{l}\text { Radical prosta- } \\
\text { tectomy, sal- } \\
\text { vage-XRT to } \\
\text { prostatic bed + } \\
\text { ADT }\end{array}$ & Rib & 0.8 & 4.25 & $7.0 \mathrm{~Gy} \times 5$ & 1.9 & $\mathrm{mR}$ \\
\hline
\end{tabular}

$A D T$ androgen-deprivation therapy, $T H$ thoracic vertebra, $L$ lumbar vertebra, $m R$ metabolic response

five patients was 11 months. The mean PSA value (mean \pm $1 \mathrm{SD})$ at the time of the first PET was $8.9 \pm 8.5 \mathrm{ng} / \mathrm{ml}$ (median $3.3 \mathrm{ng} / \mathrm{ml}$, range $0.17-21.8 \mathrm{ng} / \mathrm{ml}$ ). At follow-up PSMA PET, mean PSA values were $21.8 \pm 25.8 \mathrm{ng} / \mathrm{ml}$ (median $8.7 \mathrm{ng} / \mathrm{ml}$, range $0.62-77.8 \mathrm{ng} / \mathrm{ml}$ ). This increase in PSA was due to the selection bias (repeated PET only in the case of a repeated rise in serum PSA). All patients had new lesions on follow-up PET/CT. This analysis focuses on formerly detected and irradiated lesions and the response of these lesions in the follow-up PET.

A total number of 18 metastatic deposits were detected at the first PSMA PET prior to radiotherapy. The PET-positive tumor volume was $5.9 \pm 13.3 \mathrm{~cm}^{3}$ (median $1.25 \mathrm{~cm}^{3}$, range $\left.0.1-58.8 \mathrm{~cm}^{3}\right)$. The mean $\mathrm{SUV}_{\max }$ value of all 18 metastatic lesions was $19.9 \pm 23.3$.

In all, 14 metastatic lesions were bony metastases; 5 metastases were located in the spine, five in the ribs and the others in pelvic bones $(N=2)$, the scapula and the humeral bone (each $N=1$ ). All lesions were treated with a hypofrationated regimen (35 Gy in five fractions). Four metastatic lesions were lymph node metastases; they were treated either with $50 \mathrm{~Gy}$ in conventional fractionation followed by a boost of $7 \mathrm{~Gy} \times 2$ (in a patient who had previously undergone salvage radiotherapy to the prostatic bed) or with four (in one case) or five fractions (in another case) with 7 Gy. All patients completed radiation treatment without interruptions or severe adverse events. No acute toxicity and no late side effects were observed.

\section{Metabolic response}

The mean interval between the end of radiotherapy and the follow-up PET/CT was 3 months (range 1.9-15 months). The mean $\mathrm{SUV}_{\max }$ value of all 18 metastatic lesions decreased from $19.9 \pm 23.3$ prior to RT to $5.4 \pm 4.6$ at post-radiotherapy PSMA PET/CT. Of 18 lesions, 14 (78\%) showed 
Fig. 1 Impact of interval between radiotherapy and follow-up PSMA PET/CT on metabolic response (change in $\left.\mathrm{SUV}_{\max }\right)$. Response improved significantly with longer follow-up

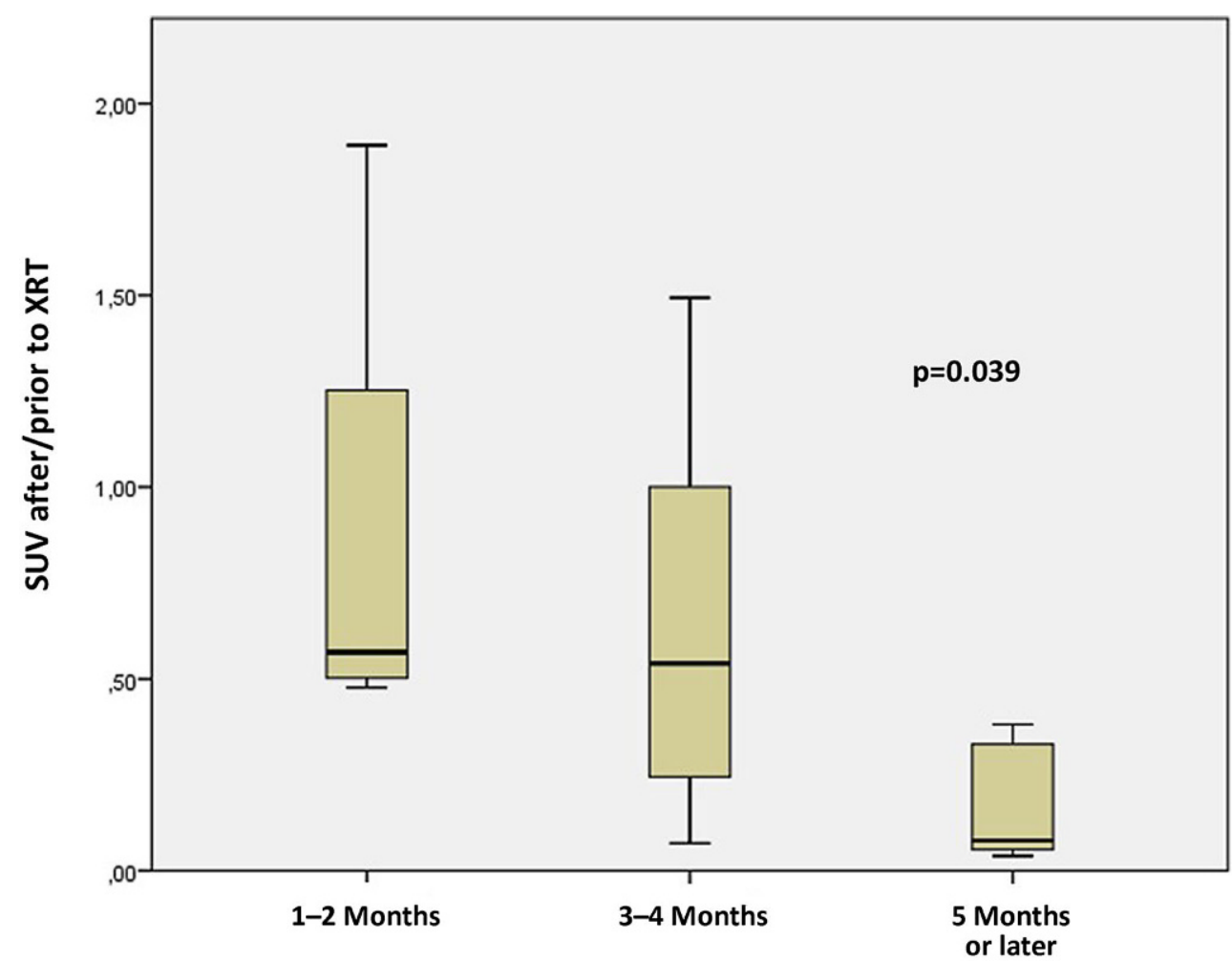

Interval between radiotherapy and control-PSMA-PET a metabolic response on PSMA PET with a reduction of $\mathrm{SUV}_{\max }$ of at least $30 \%$, as well as a significant decrease in lesion size; in seven of these lesions (39\%), no uptake of ${ }^{68} \mathrm{Ga}$-PSMA was detectable with SUV values below the threshold on follow-up PET/CT. Two lesions showed stable disease on follow-up PET/CT and two lesions showed progression with an increase in $\mathrm{SUV}_{\max }>25 \%$ (one bone metastasis after five fractions of $7 \mathrm{~Gy}$ and a paraesophageal lymph node that was treated with only four fractions to $28 \mathrm{~Gy})$.

\section{Association between time interval and metabolic response}

There was a correlation between the time interval after radiotherapy and response ( $p=0.04$; Fig. 1$)$. The decrease in $\mathrm{SUV}_{\max }$ was more pronounced after longer follow-up. The metabolic response rate was $100 \%$ if the control PSMA PET was performed after an interval of 5 months or more.

\section{Recurrences}

New metastatic lesions were detected on all follow-up PSMA PET/CTs. All lesions were outside the irradiated areas. No progression in the irradiation volume had been observed hitherto after a metabolic response. Local progres- sion-free survival (using metabolic response as a parameter for local control) at the irradiated sites was $88 \%$ after 1 year; for lesions treated with five fractions of $7 \mathrm{~Gy}$ to a total dose of $35 \mathrm{~Gy}$, the local control rate was $100 \%$ after 1 year.

\section{Discussion}

To the authors' knowledge, this is the first report on response evaluation of metastatic lesions with follow-up PSMA PET/CT after high-dose IGRT for PSMA PETdetected oligometastases in prostate cancer. The data are preliminary and there are several limitations. First of all, the patients in this analysis were highly selected with the objective to investigate the efficacy of radiotherapy as the sole treatment in patients that were naïve with regard to systemic therapy. Moreover, patients had stable or rising PSA levels at the time when PSMA PET was repeated; this bias was due to the fact that an indication for a second or third PSMA PET was given only in cases of rising PSA. Therefore, the response of serum PSA could not be evaluated in this investigation. Thirdly, all patients had new lesions, as expected due to the PSA increase at follow-up PET. Fourthly, follow-up was relatively short at a median 
of 11 months. Nevertheless, there are some facts that are interesting for further studies.

In this investigation, the detected and treated lesions were small with median and mean volumes of $1.25 \mathrm{~cm}^{3}$ and $5.9 \mathrm{~cm}^{3}$, respectively. According to data from other investigations, the detection rate of PSMA PET is clearly higher than that of all other currently available imaging methods $[12,19]$. It is very likely that at least a relevant number of these lesions would not have been detected with routine staging procedures. Thus, PSMA PET seems to be a powerful tool for treatment planning in oligometastatic prostate cancer patients that are scheduled for local ablative therapies. A major issue for patients in whom PSMA PET is used for radiotherapy planning concerns the question of how to define the target volume for radiotherapy. This is important especially in patients scheduled for high-precision radiotherapy techniques. With regard to the primary tumor in the prostate, PSMA PET seems to overestimate the tumor volume as compared with magnetic resonance imaging (MRI) [25]. The PET-positive volume was used for target definition and additional imaging methods were not routinely used for better definition of size of the treated lesions. Overestimation of the target volume cannot be ruled out, but is probably not an issue in a single, anatomically well-defined lymph node. However, target definition may be more difficult in bony structures. PSMA PET may underestimate, at least theoretically, a microscopic extension of tumor in the bone marrow, e.g. in the iliac bone or a vertebra. Therefore, a small safety margin to cover such microscopic extension was used. The preliminary results from this investigation suggest that this approach can be used in daily clinical practice.

Secondly, high metabolic response rates of PSMA PETdetected lesions after hypofractionated radiotherapy were observed. Altogether, 39\% of all lesions were no longer detectable after radiosurgery, and a further $39 \%$ showed a metabolic partial response according to PERCIST criteria. The interval between the end of radiotherapy and followup PSMA PET was relatively short (median 3 months) and might not have been sufficient to estimate the full efficacy of radiotherapy. The best response was seen in the patient with the longest interval between radiotherapy and re-investigation, and a significant association between the followup interval and metabolic response was found. These results suggest that an interval of 6 months or more may be required to fully estimate the efficacy of radiotherapy in PSMA PET imaging.

Last but not least, hypofractionated IGRT with five fractions of $7 \mathrm{~Gy}$ is a treatment regimen with proven efficacy in the primary treatment of prostate cancer [15]. This regimen has also been used by other groups to treat metastases [13]. The results reported here confirm that this regimen is fea- sible even for metastatic sites with high efficacy and good tolerance.

In summary, the preliminary results reported here suggest that PSMA PET-detected metastatic lesions can be effectively treated with high-precision radiotherapy to the PSMA PET-positive tumor volume. The course of metabolic response in follow-up PSMA PET/CT requires further investigation. If PSMA PET is used for response evaluation, an interval of several months after radiotherapy may be required to fully estimate the efficacy of radiotherapy.

Conflict of interest R. Baumann, M. Koncz, U. Luetzen, F. Krause, and J. Dunst declare that they have no competing interests.

Open Access This article is distributed under the terms of the Creative Commons Attribution 4.0 International License (http:// creativecommons.org/licenses/by/4.0/), which permits unrestricted use, distribution, and reproduction in any medium, provided you give appropriate credit to the original author(s) and the source, provide a link to the Creative Commons license, and indicate if changes were made.

\section{References}

1. Afshar-Oromieh A, Avtzi E, Giesel FL et al (2015) The diagnostic value of PET/CT imaging with the Ga-68-labelled PSMA ligand HBED-CC in the diagnosis of recurrent prostate cancer. Eur J Nucl Med Mol Imaging 42:197-209

2. Afshar-Oromieh A, Zechmann CM, Malcher A et al (2014) Comparison of PET imaging with a Ga-68-labelled PSMA ligand and F-18-choline- based PET/CT for the diagnosis of recurrent prostate cancer. Eur J Nucl Med Mol Imaging 41:11-20

3. Bluemel C, Krebs M, Polat B et al (2016) 68Ga-PSMA-PET/CT in patients with biochemical prostate cancer recurrence and negative 18F-choline-PET/CT. Clin Nucl Med 41:515-521

4. Bostwick DG, Pacelli A, Blute M, Roche P, Murphy GP (1998) Prostate specific membrane antigen expression in prostatic intraepithelial neoplasia and adenocarcinoma: a study of 184 cases. Cancer 82:225622-225661

5. Budaus L, Leyh-Bannurah SR, Salomon G et al (2016) Initial experience of 68Ga-PSMA PET/CT imaging in high-risk prostate cancer patients prior to radical prostatectomy. Eur Urol 69:393-396

6. Ceci F, Uprimny C, Nilica B et al (2015) Ga-68-PSMA PET/CT for restaging recurrent prostate cancer: which factors are associated with PET/CT detection rate? Eur J Nucl Med Mol Imaging 42:1284-1294

7. Demirkol MO, Acar O, Ucar B, Ramazanotlu SR, Satlican Y, Esen T (2015) Prostate-specific membrane antigen-based imaging in prostate cancer: impact on clinical decision making process. Prostate 75:748-757

8. Dietlein M, Kobe C, Kuhnert $G$ et al (2015) Comparison of [18F]DCFPyL and [68Ga]-PSMA-HBED-CC for PSMA-PET imaging in patients with relapsed prostate cancer. Mol Imaging Biol 17:575-584

9. Eiber M, Maurer T, Souvatzoglou M et al (2015) Evaluation of hybrid Ga-68-PSMA ligand PET/CT in 248 patients with biochemical re-currence after radical prostatectomy. J Nucl Med 56:668-674

10. Freitag MT, Radtke JP, Hadaschik BA et al (2016) Comparison of hybrid Ga-68-PSMA PET/MRI and Ga-68-PSMA PET/CT in the evaluation of lymph node and bone metastases of prostate cancer. Eur J Nucl Med Mol Imaging 43:70-83 
11. Giesel FL, Fiedler H, Stefanova M et al (2015) PSMA PET/CT with Glu-urea- Lys-(Ahx)-[Ga-68(HBED-CC)] versus 3D CT volumetric lymph node assessment in recurrent prostate cancer. Eur J Nucl Med Mol Imaging 42:1794-1800

12. Herlemann A, Wenter V, Kretschmer A et al (2016) 68Ga-PSMA positron emission tomography/computed tomography provides accurate staging of lymph node regions prior to lymph node dissection in patients with prostate cancer. Eur Urol 70:553-555

13. Ingrosso G, Trippa F, Maranzano E, Carosi A, Ponti E, Arcidiacono F, Draghini L, Di Murro L, Lancia A, Santoni R (2017) Stereotactic body radiotherapy in oligometastatic prostate cancer patients with isolated lymph nodes involvement: a two-institution experience. World J Urol 35:45-49

14. Kabasakal L, Demirci E, Ocak M et al (2015) Evaluation of PSMA PET/CT imaging using a Ga-68-HBED-CC ligand in patients with prostate cancer and the value of early pelvic imaging. Nucl Med Commun 36:582-587

15. King CR, Brooks JD, Gill $\mathrm{H}$ et al (2012) Long-term outcomes from a prospective trial of stereotactic body radiotherapy for low-risk prostate cancer. Int J Radiat Oncol Biol Phys 82:877-882

16. Morigi JJ, Stricker PD, van Leeuwen PJ et al (2015) Prospective comparison of $18 \mathrm{~F}$-fluoromethylcholine versus 68Ga-PSMA $\mathrm{PET} / \mathrm{CT}$ in prostate cancer patients who have rising PSA after curative treatment and are being considered for targeted therapy. J Nucl Med 56:1185-1190

17. Muldermans JL, Romak LB, Kwon ED, Park SS, Olivier KR (2016) Stereotactic body radiation therapy for oligometastatic prostate cancer. Int J Radiat Oncol Biol Phys 95:696-702

18. Perera $M$ et al (2016) Sensitivity, specificity, and predictors of positive 68gallium-PSMA positron emission tomography compared to conventional imaging in lymph node staging of 130 consecu- tive patients with intermediate to high risk prostate cancer. J Urol 195:1436-1443

19. Perera M, Papa N, Christidis D, Wetherell D, Hofman MS, Murphy DG, Bolton D, Lawrentschuk N (2016) Sensitivity, specificity, and predictors of positive 68Ga-prostate-specific membrane antigen positron emission tomography in advanced prostate cancer: a systematic review and meta-analysis. Eur Urol 70:926-929

20. Plut EM, Hinkle GH (2000) 111 In-capromab pendetide: the evolution of prostate specific membrane antigen and the nuclear imaging of its 111In-labelled murine antibody in the evaluation of prostate cancer. BioDrugs 13:437-447

21. Qiu S, Yang L, Deng L, Liu L, Han P, Wei Q (2016) Efficacy and safety of prostate-targeted local therapy in patients with newly diagnosed oligometastatic prostate cancer: a systematic review and meta-analysis. Lancet 388(Suppl 1):S 84

22. Silver DA, Pellicer I, Fair WR, Heston WD, Cordon-Cardo C (1997) Prostate-specific membrane antigen expression in normal and malignant human tissues. Clin Cancer Res 3:81-85

23. van Leeuwen PJ, Stricker P, Hruby G, Kneebone A, Ting F, Thompson B, Nguyen Q, Ho B, Emmett L (2016) (68)Ga-PSMA has a high detection rate of prostate cancer recurrence outside the prostatic fossa in patients being considered for salvage radiation treatment. BJU Int 117:732-739

24. Wahl RL, Jacene H, Kasamon Y, Lodge MA (2009) From RECIST to PERCIST: evolving considerations for PET response criteria in solid tumors. J Nucl Med 50(Suppl 1):122S-150S

25. Zamboglou C, Wieser G, Hennies S, Rempel I, Kirste S, Soschynski M, Rischke HC, Fechter T, Jilg CA, Langer M, Meyer PT, Bock M, Grosu AL (2016) MRI versus 68Ga-PSMA PET/CT for gross tumour volume delineation in radiation treatment planning of primary prostate cancer. Eur J Nucl Med Mol Imaging 43:889-897 